\title{
Social determinants of health: working continuously towards change
}

\author{
Thomas Abel
}

Published online: 17 June 2010

(C) Swiss School of Public Health 2010

\section{Dear Reader,}

Following the Commission's Report in the fall of 2008 (WHO 2008), IJPH started a first series of editorials on The social determinants of health $(\mathrm{SDH})$ in December 2008. Since then, internationally renowned Public-Health experts (including two members of the Commission) shared with our readers their insights and elaborated on more specific issues that have emerged from the report. Perhaps most prominent in this discussion were issues of measurement and data interpretation, the type of research that is needed, and more general concerns with fundamental values and goals that could drive societal change for the better.

The discussions on measurement covered a broad range of questions. Geyer (2010) argued that: "time is ready for using data from different sources and to combine them in a meaningful way". Such a call applies to countries, in which such data is available. However, in other countries including those from Eastern Europe this is often not the case. On that, Madarasova-Geckova (2009) emphasized that building a minimum health equity surveillance system in all countries would help to move the SDH agenda forward. She also underlined the problem that due to lack of such data, "certain groups might be overly supported, while others might be neglected". Clearly, area-level data systems seem to be needed. But even if those data were available, careful interpretation would be required. As Kunst (2009) argued, special attention needs to be paid to

T. Abel ( $\square)$

Division of Social and Behavioural Health Research, Institute of Social and Preventive Medicine, Bern, Switzerland e-mail: abel@ispm.unibe.ch constructing valid deprivation indices, and controlling for regional variations in potential confounders. Beyond regional and national variation in confounders and other data problems, there are challenges to be met when it comes to political consequences. Referring to profound changes in our societies such as accelerated economic, technological and cultural globalization, Siegrist (2008) stressed that we need to consider very carefully the "crosscultural generalizability of existing explanatory models of social inequalities in health".

The discussion on methodological issues had one gravitation centre on the question of what type of research is needed and would be most helpful. A clear statement was put forward by Potvin (2009) holding that "We do not need more of the same research describing the problem as we have been doing for the past 30 years", calling instead for a drastic shift towards intervention research. This was reinforced by McQueen (2009), who argued for a move of the applied research agenda to the assessment of interventions that will change the social determinants: "Unless effective interventions change the social determinants, we will be looking at the same or a worsening "gradient" in a decade. And, the historical story will continue as usual".

Supplied with more appropriate research that will demonstrate how we can change the SDH to the better yet, another challenge arises: how can we "bridge the gap between our health knowledge and political decision making" (Koskinen and Puska 2009). Clearly, such policies have to deal with inequalities at the national and global level. At both levels one issue sticks out as the most challenging of all: "power and resources should be shared more equally among citizens" (Vagerö 2008); only then will lasting improvements of daily living conditions for the majority follow. Measures recommended in the SDH report include more fair arrangements of global trade, regulation 
of trade with health-damaging commodities, global tax options or massive programs for global "slum upgrading".

A final issue that figured prominently in our editorial series is that of the role of the state and its citizens. When is a "strong state" needed? What is the role of the individual, the active citizen when it comes to health inequalities? Regarding the first question, Corbett (2009) argued that it is possible to "demonstrate that modern public-health regulation can be efficient and effective, often surprisingly popular and relatively free of red tape and the taint of overbearing government intervention in the lives of its citizens". And, on the role of the individual Marmot (2009) made the point, that the measures we take need to include "the conditions that empower people and enable them to lead flourishing lives".

At the end of this first series we had gathered a fine collection of editorials from which all interested in the SDH, can draw on in their own research and cross-fertilize their discussions. The success of that series encouraged us to plan for a second round of editorials, continuing to reflect on substantive issues and methodological challenges in social-inequality research.

When thinking about who we should invite this time, we realized that there is a peculiar problem of ageing in the SDH approach: the ageing of our community of Public Health researchers. Public Health researcher and advocates as individuals grow older and will eventually leave the field - while the problem of social inequality is likely to remain relevant.

"Closing the gap in a generation" is a laudable goal and a strong motivational call but, we must be aware that it will take more than one generation of Public Health experts to keeping the gap closed (in the ideal case) or closing it further (in the more realistic case).

There is little doubt, that the SDH approach will need a fair amount of continuity, even across generations. To facilitate that continuity we invited a second series of editorials on the SDH but this time, only from those experts who are likely to be the one's that will (still) deal with the challenges of social inequality and health in the next decades. What do they think of the Commission's Report? What do they find missing in the ongoing discussion of the report?

Starting with the current issue, we present their thoughts and critiques in a new series of six editorials published in three consecutive issues. The series will keep SDH issues highly visible on the agenda of IJPH and hopefully, add some fresh thinking to the current discourse on social inequality and health. We would like to thank all six authors, and invite you, Dear Reader, to join us in this experience of a trans-generational Public-Health discourse on the SDH.

\section{References}

Corbett S (2009) Modernising public-health infrastructure. Int J Public Health 54:301-302

Geyer S (2010) Research on social determinants and health: what sorts of data do we need? Int J Public Health 55:1-3

Koskinen S, Puska P (2009) From social determinants to reducing health inequalities. Int J Public Health 54:53-54

Kunst AE (2009) Socioeconomic inequalities in health in Central and Eastern Europe: synthesis of results of eight new studies. Int $\mathbf{J}$ Public Health 54:197-200

Madarasova-Geckova A (2009) Can research contribute to the public's capacity for activities that reduce socioeconomic inequalities in health? Int J Public Health 54:201-202

Marmot M (2009) Social determinants and adolescent health. Int J Public Health 54:S125-S127

McQueen D (2009) Three challenges for the social determinants of health pursuit. Int J Public Health 54:1-2

Potvin L (2009) Yes! More research is needed; but not just any research. Int J Public Health 54:127-128

Siegrist J (2008) Social determinants of health-a cross-cultural perspective. Int J Public Health 53:277-278

Vagerö D (2008) Closing the global health gaps in a generation-how is it possible? Int J Public Health 52:279-280

WHO Commission on Social Determinants of Health (2008) Closing the gap in a generation. Health equity through action on the social determinants of health. Geneva. http://whqlibdoc.who.int/ publications/2008/9789241563703_eng.pdf. Accessed 17 May 2010 